20-22 March, 2020

Berlin, Germany $10^{\text {th }}$ International Conference on

Humanities, Psychology \& Social Sciences

\title{
The Techno-Pleasure Society
}

\author{
Dr. Asher Jospe
}

Tel Aviv University

\begin{abstract}
Human society is undergoing radical changes in recent decades. The technology progress has brought about unprecedented capability of mankind to dominate nature. This turn of events leads to the question whether Herbert Marcuse's interpretation of the world society as one dimensional has changed or stayed firm. This question of world interpretation is principal to the issue of consciousness which in itself is a necessary condition for any social transformation. So, we can rephrase the question as: Does the relentless technology evolution lead to the generation of the consciousness which is required for the social transformation? According to Marcuse society is in a state of repression which is affected by technology. Society has become one where technology rationality rules. According to him, the terms of this repression include in them the negation of all possibilities to achieve transformation and thus freedom. In other words, the question is: does technology carries any implications for Emancipation? In recent years technology is evolving in an unprecedented way which puts ever increasing power and capabilities in the hands of the Subject, the human being. This power manifests itself in GPS systems; on line communications to the palm of the individual used for shopping, bills payments; advertising and more. BUT, above all this power is used for entertainments and pleasure. Mankind is maximizing its desire for pleasure thru the use of the hand-held smartphones. This pleasure is explicated in chat mode communications like WhatsApp but mostly in watching movies, video clips and listening to music, all available 24/7 nonstop, with no fee. The relentless drive to produce pleasure (as per Freud) is one of the most power drives in society. In addition to producing pleasure it provides a mechanism of escape from day to day, ongoing hardships of life, and thus is extremely popular. Indeed, the use of handheld smart devices has increased intensively and extensively beyond anyone's imagination. This is a phenomenon which provides relief (illusionary, admittedly) to the individual from his day to day hardships, and thus furthers any thought of social transformation. 2 In summary, technology has great achievements for mankind, especially in the medical space. One clear consequence of its evolution is the suspension of thought of the need for transformation. This need is put on hold by deriving pleasure from this platform. And so, it turns out that technology brings a lot of pleasure to the individual and at the same time, because of it, suspends any thought of social transformation. This is a kind of repression which is an unintended consequence, but nevertheless, it is a very powerful force in eliminating any antagonistic and dissenting voices in society.
\end{abstract}

Keywords: Transformation, Pleasure, Technology, Freud, Society 